\title{
Aldosterone-Cortisol Cosecreting Adenoma
}

\author{
${ }^{1}$ Navneet Tripathi, ${ }^{2}$ Roma Pradhan, ${ }^{3}$ Manoj Jain, ${ }^{4}$ Eesh Bhatia, ${ }^{5}$ Amit Agarwal
}

How to cite this article: Tripathi N, Pradhan R, Jain M, Bhatia E, Agarwal A. Aldosterone-Cortisol Cosecreting Adenoma. World J Endoc Surg 2015;7(2):53-54.

\section{Source of support: Nil}

\section{Conflict of interest: None}

\section{INTRODUCTION}

A 47-year-old lady from Nepal presented with profound proximal muscle weakness and weight gain for last 3 years. Patient was a known hypertensive for last 3 years which was poorly controlled on 2 antihypertensive drugs. Patient was obese $(B M I=29.9)$ with rounding of facies. Ultrasound (USG) abdomen and a subsequent cone beam computed tomography $(\mathrm{CECT})$ showed a $2.5 \times 2.1 \mathrm{~cm}$ heterodense right adrenal lesion. Hormonal evaluation revealed ACTH independent hypercortisolism. Serum aldosterone and ARR were raised however, saline loading test was negative for confirmation of aldosteronism. Patient underwent laparoscopic adrenalectomy under steroid cover. Cut section of specimen showed golden yellow tumor admixed with islet like distribution of $\tan$ /brown portion. Histopathology showed nodules composed of 2 types of cells, i.e. clear and compact cells consistent with aldosterone and cortisol cosecreting adrenal adenoma (A/CPA).

Aldosterone and cortisol co-producing adenomas (A/CPA) are considered a distinct rare subtype of primary aldosteronism (PA). ${ }^{1}$ It is important to detect cosecretion from adrenal tumors as they have unique clinical features, impact on nature of perioperative management and difficult interpretation of diagnostic/localizing tests. A typical imaging features suggestive of cosecretion include larger tumor size in a diagnosed PA patient and Magnetic resonance imaging (MRI) finding of inhomogeneous signal intensity and absence of low signal on out of phase images. These tumors are

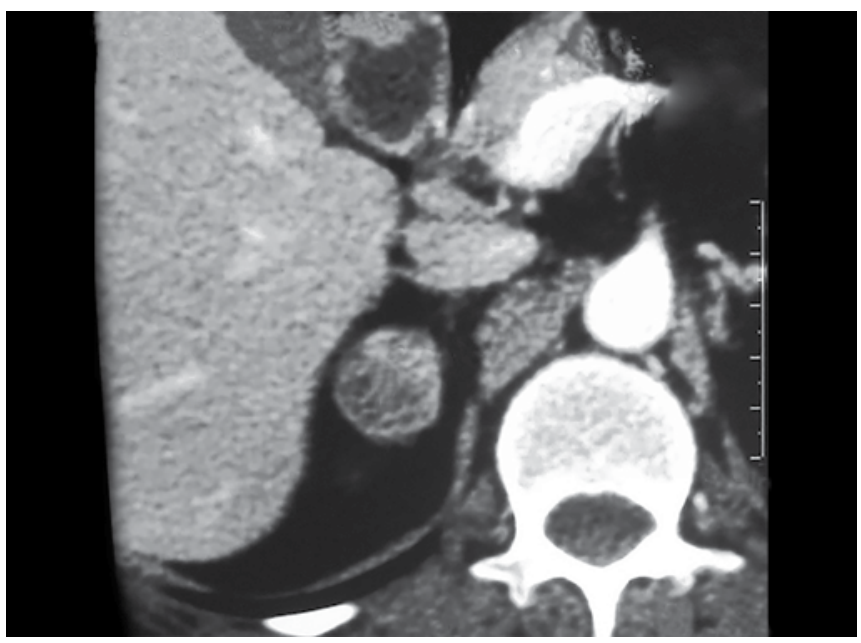

Fig. 1: Cone beam computed tomography abdomen : $2.5 \times 2.1 \mathrm{~cm}$ heterodense lesion arising from medial limb of right adrenal gland with maintained fat planes

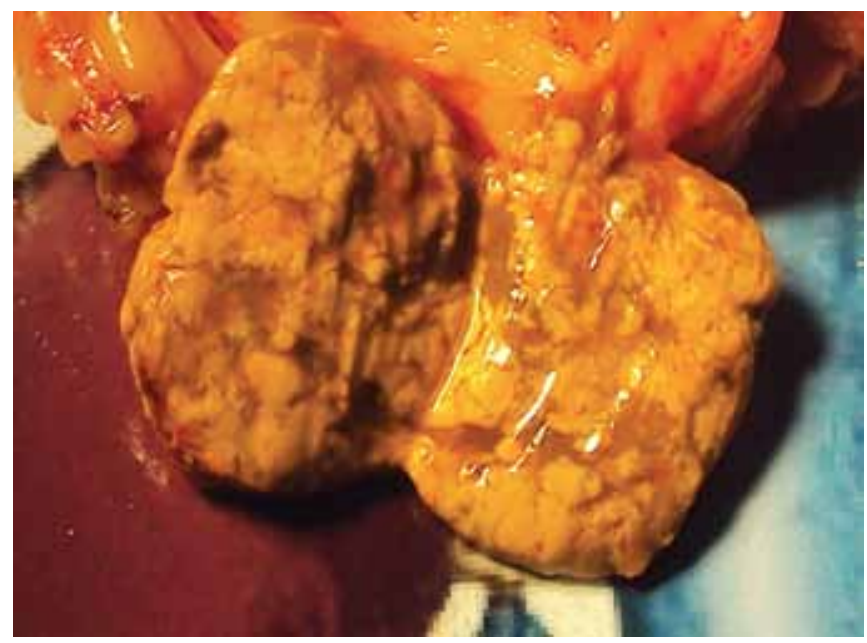

Fig. 2: Right adrenalectomy specimen: Cut section showing golden brown part admixed with brown portion distributed in an islet like pattern

\footnotetext{
${ }^{1,2}$ Senior Resident, ${ }^{3-5}$ Professor

1,2,5 Department of Endocrine Surgery, Sanjay Gandhi Post Graduate Institute of Medical Sciences, Lucknow, Uttar Pradesh, India

${ }^{3}$ Department of Pathology, Sanjay Gandhi Post Graduate Institute of Medical Sciences, Lucknow, Uttar Pradesh, India

${ }^{4}$ Department of Endocrinology, Sanjay Gandhi Post Graduate Institute of Medical Sciences, Lucknow, Uttar Pradesh, India

Corresponding Author: Amit Agarwal, Professor, Department of Endocrine Surgery, Sanjay Gandhi Post Graduate Institute of Medical Sciences, Lucknow, Uttar Pradesh, India, e-mail: amit@sgpgi.ac.in
} 


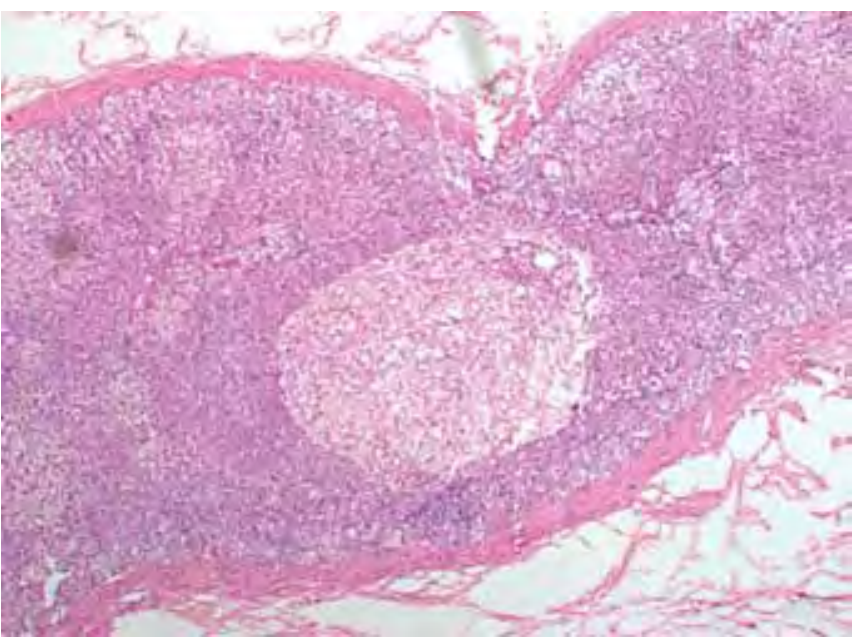

Fig. 3: Histomicrophotograph (low magnification): central area of clear cells (Zona Glomerulosa type cells) surrounded by compact cells (Z Fasciculata type cells)

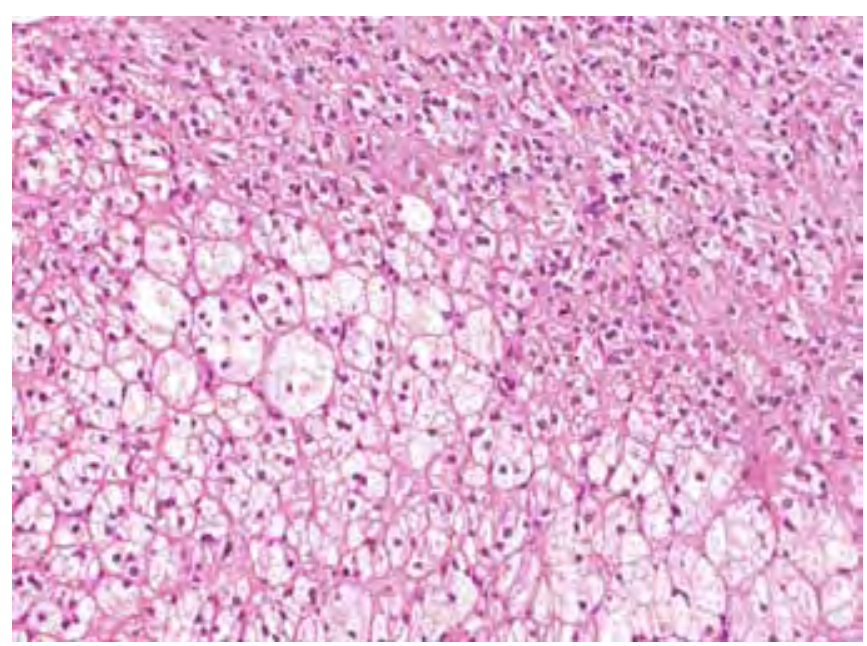

Fig. 4: Histomicrophotograph (High magnification): Aldosterone secreting clear cells are larger with lipid laden vacuoles and clear cytoplasm; cortisol secreting compact cells are smaller and eosinophilic

invariably composed of aldosterone secreting (clear cells) golden yellow part and cortisol secreting (compact cells) tan/ brown art. $^{2}$ Undetected cortisol cosecretion in a diagnosed case of aldosteronism may lead to fatal post adrenalectomy adrenal crisis. Hence, all aldosterone producing adenomas (APA) should also be screened for hypercortisolism to rule out cosecretion of cortisol.

\section{REFERENCES}

1. Spath M, et al. Sporadic solitary aldosterone and cortisol cosecreting adenomas: endocrine, histological and genetic findings in a subtype of primary aldosteronism. Hypertension Res 2010;33:467-472.

2. Adachi J, Hirai Y, Terui K, Nakano T, Fukuda Y, Suda T, Sasano H. Report of 7 cases of adrenal tumors secreting both cortisol and aldosterone. Internal Med 2003 Aug;42(8):714-718. 